\title{
¿Liberar los animales? Un eslogan inmoral y absurdo*
}

\author{
Francis Wolff \\ Traducción del francés al español \\ de Luis Alfonso Palau Castaño \\ DOI: $10.22395 /$ csye.v5n10a15
}

¿Liberar los animales? ¿Quién podría estar contra un objetivo aparentemente tan generoso? ¿Quién no se va a indignar viendo las condiciones de crianza, de trasporte y de sacrificio, inducidas por el productivismo contemporáneo? ¿Quién no se ha conmovido viendo en la tele las condiciones de vida (si es que a eso se lo puede llamar vida) de los cerdos y de las terneras? ¿Quién no se ha descompuesto al enterarse de cómo son lanzados los perros en las autopistas europeas a comienzo de las vacaciones del verano ${ }^{1}$

Es claro que la protección animal hace parte hoy de nuestros deberes.

Sin embargo, cuando se habla de liberar los animales, no se quiere decir "mejorar sus condiciones de vida". Se quiere decir otra cosa; lo que se quiere decir es dejar de explotar. Se da por entendido que los animales estarían subyugados por el hombre. Esto implica que el proceso de domesticación por el que el hombre, al menos desde el neolítico, aprendió a vivir con ellos, a criarlos, a mantenerlos, a cuidarlos, a amaestrar algunas especies, a crear nuevas variedades, razas, de hecho no habría sido sino una gigantesca empresa de esclavitud. Lo que quiere decir que, de la misma manera que hace 11000 años puso en marcha su proceso de civilización (se auto-domesticós al inventar la agricultura y la ganadería, domesticando para ello plantas y animales, habría en la actualidad que desprenderse de tal "barbarie", liberando según ellos a los animales a los que avasalla idesde hace más de cien siglos!

Tomemos esta extraña idea en serio y veamos lo que implica. Liberemos pues los animales. Habría entonces que comenzar por liberar la especie más dependiente del hombre, la que solo existe en estado doméstico. Y no es el marrano o el perro, sino la mariposa de la morera (bovibix mori), que los chinos

Tomado de: Jean Birnbaum (dir.) Qui sont les animaux?, París: Folio essais, 2010, pp.180-193. Publicado el 4 de julio de 2015 por Philocolibri. Traducción del francés al español de Luis Alfonso Palau Castaño, Medellín, noviembre 23 de 2016.

1 (iCómo se los abandona en el Peñol actualmente!...). 
inventaron para producir la seda ${ }^{2}$. Dejemos de producir seda y no sigamos por tanto criando esta especie de mariposa. Liberémosla imatémosla!

Liberemos, liberemos pues. Abramos las conejeras, liberemos a los conejos y peor para Australia que estuvo a punto de perecer (ella y todo su ecosistema) bajo el peso de aquella invasión. Liberemos los visones en la Dordoña, sin preocuparnos por la catástrofe ecológica que ello traerá, puesto que hay que darles a todos esos pobres animales la "Libertad" (seguro que ellos no pedían tanto). Liberemos del hombre las ovejas (después de todo ¿sí tenemos realmente necesidad de lana cuando hay tantas materias sintéticas?), pero también liberemos los lobos sin preocuparnos de las ovejas; y liberemos los osos sin ponerles cuidado a los campesinos de los Pirineos y a sus rebaños (pues sí que les va a tocar a ellos ilibrarse también de los osos!). Aprovechemos también para liberar a los gatos de su dependencia de nuestras casas, que vuelvan a cazar en los bosques o en las cavas; y pensemos en liberar las ratas de los gatos a los que hemos liberado. Y liberemos nuestros perros, cortémosles las traíllas, dejémoslos vagabundear, solos, sin dueños, puesto que el amo es, por definición, el que los domina, los sujeta, los explota. Y, como consecuencia, tendremos que no volveremos evidentemente a consumir carne, ni de pescado ni de crustáceos. Seremos, entonces, ovolactovegetarianos. Pero tampoco tendremos la tierra prometida por la Biblia, aquella "por donde corren ríos de leche y miel", puesto que estas provienen de la explotación de los animales. Seremos vegetarianos del todo. Pero tampoco tendremos suéteres de lana, ni zapatos de cuero, ni plumas de avestruz; no usaremos ninguna materia que provenga de nuestros hermanos animales. Seremos pues veganos. (Y entre paréntesis: si toda crianza es una forma de servidumbre, ¿cómo vamos a hacer para liberar a los pulgones que crían las hormigas ${ }^{3}$ ? ¿Tendremos que esperar la formación de un hipotético "Frente de liberación" de los pulgones? ¿O más bien podremos contar con una toma de consciencia por parte de las hormigas de su poder extorsivo? ¿O también en este caso no contaremos sino con nosotros mismos, nosotros la vanguardia liberadora de los animales, y forzar a los pulgones, las mariposas, las abejas, los gatos, los perros, las ovejas, los pollos, las cotorras, los salmones, las ostras, los peces rojos, a que se liberen, a que por fin sean libres?). ¿Hasta dónde nos llevará esta locura "liberacionaria"? Hasta el punto que, tomando conciencia de que la mayor parte de esas variedades, razas y especies solo deben su sobrevivencia a su relación con el hombre, y que una vez "liberadas" no podrían retornar a retozar en estado salvaje sin estar condenadas inmediatamente a muerte, tomaremos la única medida liberatoria eficaz y nos decidiremos a castrar y a esterilizar a todos los animales domésticos de la tierra con el fin de asegurarnos de que ya no habrá nunca animales víctimas de los hombres.

\footnotetext{
2 http://historiaybiografias.com/seda/ Paláu».

3 ıhttp://www.bayergarden.es/Cuida-de-tus-plantas/Plagas-del-Jardin/Pulgones-y-Hormigas Paláuı. 
Es lo que preconiza el pensador estadounidense Gary Francione, que se atreve a empujar la lógica de la "liberación animal" hasta dicho extremo ${ }^{4}$. ¿Pero será absurdo? No, en efecto es insensato. Pero es sin embargo absolutamente coherente. Es incluso el único tipo de medida que deriva racionalmente del principio mismo de la "liberación animal", eslogan tan ingenuo como irresponsable. Se ve que, sí hay practicantes de la "liberación animal" que son terroristas asumidos (ver el Animal Liberation Front ${ }^{5}$ ), hay también teóricos de la liberación animal que son verdaderos peligros públicos.

Por supuesto que es necesario recordar que al liberar así a los animales uno se priva de una buena parte de lo que ha constituido la humanidad del hombre, que se humanizó por la domesticación rel hombre fue el primer animal que se auto-domesticó, la crianza, el amaestramiento, la doma de las otras especies, pero también evidentemente de una parte de lo que hace la animalidad de numerosas especies animales. Pero, qué importa esto, puesto que el Hombre es el enemigo número uno, el animal malo que dominó a todos los otros (itan gentiles ellos!) y que debe, de acá en adelante, iforzarlos a que se liberen de su propia servidumbre! ${ }^{6}$

¿A qué se debe esta locura "liberacionaria"? A numerosas causas, ... pero también es un síntoma.

Hay primero factores sociológicos, entre los cuales hay que distinguir realidades e idealidades. El factor real es aquel del que hemos partido: la Modernidad ha entrañado una indiscutible degradación de las condiciones de crianza de algunos animales destinados al consumo humano (especialmente cerdos, terneros y pollos), reduciéndolos al estado de mercancías. La toma de consciencia de este fenómeno terminó por conmover con toda legitimidad a las poblaciones, que encajan por lo demás mal el precio que tendrían que pagar por un eventual retorno a una ganadería más extensiva, o más respetuosa de las condiciones de vida de las bestias.

Y en paralelo a estos cambios reales, existen las mutaciones en las representaciones. El crecimiento de la urbanización ha hecho perder a los habitantes de esas mismas sociedades industriales, todo contacto con la naturaleza salvaje; esas poblaciones olvidaron la lucha ancestral de los hombres contra las especies dañinas (piénsese en los lobos diezmadores del ganado o en las ratas portadoras

\footnotetext{
4 (http://www.vegetarianismo.net/liberacionanimal/francione.htm Paláuı.

5 ıttps://es.wikipedia.org/wiki/Frente_de_Liberaci\%C3\%B3n__Animal\#Reivindicaci.C3.B3n_de_las_acciones_directas Paláus.

6 imposible no compartir un mensaje que me hizo llegar un amigo cuando le di a conocer este texto: "A propósito de liberar los animales, no hay que liberar las (pulgas) del circo de pulgas de María Fernanda Cardoso..." Paláus.
} 
de la peste), e ignoran igualmente la que siguen manteniendo hombres en otras latitudes (pensemos en las langostas que arrasan las cosechas africanas, o incluso en los perros callejeros que infestan cantidad de ciudades del Tercer Mundo). Pero esas mismas condiciones urbanas han sido las encargadas de separar a los hombres de la vida de los animales como se daba en el entorno doméstico tradicional, cuando todos cohabitaban en torno de la casa y que se sacrificaba al marrano en los días de fiesta. Hemos roto con los animales reales, ya sean salvajes o domésticos. Y en lugar de estos se desarrolló de forma exponencial, en estas últimas décadas, un nuevo tipo de fauna, de donde nació una nueva relación con la animalidad; los animales de compañía a través de los cuales se ve todo el reino animal. Por primera vez en la historia, los hombres ya solo tienen que ver, desde mediados del siglo XX, con animales que ellos crían para que no hagan nada, simplemente para que estén ahí, echados en el canapé del salón y para intercambiar caricias y afectos con sus amos. Los únicos animales que los urbanos de las sociedades occidentales conocen son: o sus bebecitos que hacen parte de su familia (en los centros de las ciudades, porque a veces en los arrabales, son molosos; pero, bueno, esta es otra historia), o los animalesvíctimas criados en batería que ven por la televisión. Todo eso está bien lejos de la realidad animal y de su inmensa variedad. En el imaginario contemporáneo el animal no es ya lo que era en el imaginario clásico, la bestia aterradora o el animal de trabajo, sino que es la víctima o el fetiche. Y el reino de la naturaleza ya no es, como en los modelos filosóficos antiguos, la ley de la jungla (la guerra de todos contra todos) sino un mito dysneylandizado y bio-aseptizado donde reina la armonía preestablecida entre animales uniformemente graciosos, un universo que sería eternamente pacífico y sereno sin la intervención del único predador... el Hombre. Pero este es un mito completamente elaborado por la civilización industrial, el de una naturaleza apacible (paraíso perdido en el que los animales estaban libres), y en el que el Hombre con una gran $\mathrm{H}$, representante del Mal, es el verdugo del Animal con A mayúscula, la inocente víctima; esto permite meter todos los animales en el mismo saco (siguiendo la habitual visión antropomorfista); el gato y el ratón, el lobo y el cordero, el perro y la pulga, todos libres (y, sobre todo, libres de comerse entre todos). Este es el fantasma que alimenta los ideales revolucionarios de la "liberación animal".

Pero esta ideología es ante todo un síntoma. Síntoma sin duda del derrumbe del horizonte revolucionario mismo, en todo caso del desmoronamiento de las creencias que se tenían en la salvación común, signo del ascenso de una desconfianza con respecto a todo ideal de liberación política o social, de una pérdida de confianza en los proyectos colectivos de salir adelante; ya lo político solo aparece como el juego moroso de las ambiciones personales o de las alternancias partidistas. Ayer, todo era política. Hoy ya nada es político, todo es ético. Se han desviado los conceptos políticos forjados para pensar hasta 
hace poco las ataduras de los hombres; se habla de "liberación animal", como anteriormente se hablaba de liberación de ciertos pueblos o de algunas clases, en momentos en que todavía hay tantos hombres esclavizados en el mundo, y iellos sí realmente! Se habla de explotación de los animales, en el sentido en que se hablaba ayer de explotación del hombre por el hombre (que, sin embargo, no ha dejado de existir ni ha disminuido su explotación). Se califica incluso algunas formas de sacrificio de "genocidio animal"; la expresión estremece, como si no fuera un medio de banalizar el horror de los crímenes contra la humanidad. (Al querer sensibilizarnos por la suerte de algunos animales, corremos el riesgo de insensibilizarnos a los más grandes dramas de la historia, si todo es igual y si las palabras pierden su sentido). No, decididamente esos conceptos políticos no son los buenos instrumentos para pensar nuestros deberes con respecto a los animales que hemos colocado bajo nuestra custodia.

Pero esta nueva ortodoxia "animalista" es también el síntoma de otra ideología. La idea que se impone es que la moral no reposa sobre leyes universales, ni sobre reglas comunes o sobre contratos (implícitos o no), ni sobre la reciprocidad o sobre el reconocimiento del otro como persona, ni sobre deberes colectivos que hay que respetar, o sobre virtudes por transmitir, sino sobre el solo valor intrínseco e individual que se les debe conceder a todos los seres que podrían ser las víctimas de nuestra conducta malévola (niñitos, viejos seniles, disminuidos mentales, animales). A esta moral centrada sobre la solo idea de víctima, corresponde el ascenso irreprimible de la noción de "derechos subjetivos"; ya no se habla de virtudes educativas o de deberes de los padres, sino de los derechos del niño; ya no se habla de igualdad o de justicia, sino de los derechos de la mujer; y por supuesto, y en fila con tales derechos, ahora los derechos del animal. Esta noción, también importada indebidamente del dominio político, reposa sobre una reinterpretación moralista de la idea de derechos del hombre. Los derechos del hombre afirmaban la necesidad de reconocer un territorio de independencia de los sujetos con respecto a la omnipotencia de los Estados. Ellos suponían correlativamente la afirmación de la igualdad fundamental de todos los hombres, y proclamaban por consiguiente que todas las formas de discriminación, racial, religiosa, sexual, etc., debían ser combatidas. Pero, ahora que la discriminación racial se ha quedado sin fundamento puesto que las razas no existen, tampoco tiene sentido hablar de discriminación entre especies; ¿vamos a decir que los lobos discriminan a las ovejas cuando se las comen?; esto no tiene sentido. Y mientras que existe un sentido cuando se pretende fundar la igualdad de derechos entre los hombres sobre su común naturaleza, ¿sobre cuál identidad de naturaleza fundar la igualdad de derechos entre animales? ¿Sobre el hecho de que son vivientes y que todo viviente tendría a priori un "derecho a la vida"? Pero si hay un carácter común a los animales es que son vivientes "heterótrofos", es decir que se alimentan de sustancias orgánicas, de vegetales 
y de animales. Proclamar que todos tienen un derecho a la vida es pues una absurdidad, puesto que por definición un animal solo puede vivir en detrimento del viviente. Yo puedo hacer bonito absteniéndome de comer especies vivientes, pero eso no impedirá nunca a todas las otras especies vivientes que lo hagan, bajo pena de su propia muerte. De forma más general, la noción de derechos de los animales es contradictoria: si se le concede al lobo el derecho de vivir, se le retira ese derecho a la oveja; y si se dice que la oveja tiene derechos, ¿qué se va a hacer con el derecho natural que tiene el lobo de alimentarse? Proclamar la igualdad de los derechos de los animales es absurdo; si mi perro tiene derecho de vivir sin pulgas, la pulga no tiene derecho a cohabitar con mi perro.

Añadamos que la noción de derechos subjetivos supone una autoridad neutra encargada de hacerlos respetar; ahora bien, los únicos animales que pueden hacer respetar esos derechos son los animales humanos que son también, se dice, ilos únicos que deben respetarlos! Decididamente estamos en plena confusión. Prueba que nunca tenemos por qué calcar las normas que deben guiar nuestras relaciones con los animales sobre conceptos, como ese de "liberación" o el de "derechos", forjados para pensar las relaciones políticas de los hombres entre sí.

Un factor no menos importante que explica esta estrepitosa ola de ideología "animalista" es el cambio de paradigma científico y epistemológico del que somos testigos. En el estudio del hombre, hemos pasado del paradigma de las ciencias humanas (que dominó el siglo XX) a un paradigma biológico, o más generalmente naturalista. Las ciencias humanas estaban fundamentadas en la idea de que el hombre tenía una especificidad que lo oponía al resto de la naturaleza; especificidad de objeto que permitía justificar el particularismo de los métodos y de los conceptos de dichas ciencias; por ejemplo, la historia humana estaba fundada sobre su oposición a la noción de evolución natural; el psicoanálisis sobre la especificidad del inconsciente y de lo simbólico propiamente humano; las ciencias sociales sobre la oposición instinto/institución; la antropología cultural sobre la oposición naturaleza/cultura; la lingüística sobre la oposición lenguaje humano/comunicación animal. Por tanto, según el postulado epistemológico fundador de esas ciencias, el hombre estaba opuesto al resto de la naturaleza, en particular al animal.

El actual paradigma dominante es, por el contrario, naturalista, incluido acá el estudio de los fenómenos humanos; es la conjunción de las teorías del evolucionismo darwiniano, de la biología molecular, de las neurociencias, de las ciencias cognitivistas, etc. Tiende evidentemente a negar toda especificidad humana por razones simétricas a las precedentes. Se trata de justificar métodos y conceptos también ellos naturalizados en el estudio de los seres naturales, de los que hacen parte los hombres al mismo título que los animales. De esta 
manera, las oposiciones de antaño (hombre/animal; naturaleza/cultura) han sido sustituidas por una visión unitaria del mundo natural del que el hombre no es sino un elemento, un viviente adaptado a su medio, fruto de la selección natural, un animal como los otros.

Por esto algunos de aquí en adelante afirman que lo que hasta hace poco se proclamaba como lo propio del hombre (la vida política, la cultura, el lenguaje, el arte, lo simbólico, las reglas morales, etc.) puede ser ya atribuido igualmente al animal.

Esta es una visión falsa. Pues es tan ingenuo pretender que "el lenguaje", por ejemplo, no es lo propio del hombre, o que hay arte entre los animales, como es ingenuo pretender lo contrario. Forzosamente hay un concepto de lenguaje que engloba todas las formas de comunicación animal, y hay otro concepto de lenguaje que solo incluye el lenguaje humano (su estructura sintáctica, su poder de creatividad infinita, etc.). Y lo mismo ocurre para el arte, para la cultura, para la vida social, para la moral, para el pensamiento, etc.; todas estas cosas se las puede siempre "naturalizar" al mostrar la comunidad de todos los vivientes (y se gana acá con toda seguridad un plano de inteligibilidad), o se puede negar hacerlo buscando mostrar la especificidad de las culturas o de las sociedades humanas (y se gana aquí otro plano de inteligibilidad).

El problema comienza entonces cuando, apoyándose en un postulado fundador de las investigaciones naturalistas (la proposición "no hay especificidad humana"), se pretende tomarlo por una verdad absoluta y hacerlo jugar un rol normativo: "puesto que el hombre es un animal como los otros -se dice- debe conducirse, o no conducirse, de tal o cual manera con respecto a los otros animales". Es pues un sofisma bien conocido al que ceden la mayor parte de los ideólogos "animalistas".

Pues la falla más profunda de estos razonamientos sobre la "liberación animal" viene del concepto mismo de "animal", que no tiene para nada sentido en un contexto moral. El concepto de animal no solamente es excesivamente extensivo (puesto que va del microbio al chimpancé), sino que es contradictorio. En efecto, debe a la vez incluir al hombre, al que se proclama que es "científicamente" un animal como los otros, y excluir al hombre, del que se dice que es "moralmente" un animal opuesto a todos los otros, puesto que es el único animal que tiene un comportamiento reprensible con respecto a los otros. Ahora bien, una de dos: o es el hombre un animal como los otros, y entonces no se ve por qué debería constreñir a su propia naturaleza animal y obligarse a cumplir reglas a las que no se obliga a los otros animales, o se reconoce que el hombre solo debe abstenerse de algunas conductas con respecto a los otros animales. 
Evidentemente que la buena hipótesis es la segunda. Pero entonces habría que admitir el corte hombre/animal y conceder que es esto lo propio del hombre. ¿Qué es en efecto lo propio del hombre, si se le quiere excluir todas las propiedades naturales (a este título es un animal) pero también todas las propiedades culturales (puesto que se pretende que ellas se encuentran ya en germen en algunas especies animales)? Es la moral precisamente. El hombre no es un animal como los otros porque él es el único animal moral, en el sentido fuerte del término, es decir, el único que puede regular sus conductas siguiendo normas y teniendo valores, el único que se puede plegar a sus deberes, es decir, a no solamente desear, sino también a poder querer desear o no desear lo que desea. Debe pues ante todo reconocer que tiene deberes para con cualquier otro hombre, que como él puede plegarse a deberes, y aceptar reglas de reciprocidad; pero también puede reconocer deberes (no recíprocos) con respecto a algunos animales que no tienen por naturaleza ningún derecho, como tampoco tienen deberes.

Entonces ¿qué vamos a concluir? Es muy simple; simplemente vamos a tomar todos nuestros hilos sucesivos.

Es necesario, ante todo, dejar de lado todos los conceptos políticos que no hacen sino embrollar las pistas: liberación, explotación, derechos, etc. Hay que admitir que los animales no tienen derechos, lo que no quiere decir que nosotros no tengamos deberes para con ellos. En segundo lugar hay que cuidarse del razonamiento que pretende que el hombre es un animal como los otros; esto sería aceptar que él se conduce como una bestia o pretender que él no debe normar su conducta con respecto a los animales. Es necesario, por el contrario, afirmar que hay un corte entre el hombre y el animal, puesto que el hombre es un ser moral. Es preciso, en tercer lugar, poner cuidado en no echar a todos los animales en el mismo costal. Ese pseudo concepto de "animal" solo conduce a callejones sin salida. Por ejemplo, no podemos tener los mismos deberes con respecto a nuestros perros... y a sus pulgas; con respecto a nuestras ovejas... y a todos los otros mamíferos que pueblan las selvas, las montañas y los ríos del mundo. No se puede formular una sola regla de conducta que podamos aplicar indistintamente a todos esos animales. Y no se puede poner en el mismo plano el dolor (quizá considerable) del gobio pescado, que puede muy bien morir comido por un pez más grande que él, por ejemplo, por un orgulloso pescador de domingo, y el del perro al que se golpea a muerte por parte de su dueño que le debía protección y afecto. Lo que conviene hacer es partir de lo que son nuestras relaciones con algunos animales para determinar así los deberes diferenciados y jerarquizados que podemos tener con ciertas especies, o con respecto a algunos individuos, aquellos con los que hemos anudado relaciones de afecto recíproco o relaciones de dependencia mutua. 
Para ir rápido digamos lo siguiente. Hay en principio una división moral tripartita de los animales. Están los animales de compañía a los que nos atan relaciones afectivas individualizadas. Nos dan su afecto a cambio del nuestro. Es pues inmoral traicionarlos, por ejemplo, desembarazándose de su perro y lanzándolo a la carretera y privándolo así de su relación con su amo. Dicho de otra manera: ies inmoral querer liberarlo! Están después los animales domésticos, que hemos criado por su carne, su leche, su lana o su trabajo, y a los que nos ata una suerte de contrato de intercambio y de relaciones individualizables. Nos dan sus productos a cambio de la pastura y de nuestra protección. Puede ser moral el sacrificarlos puesto que solo viven con frecuencia para esto. Pero es inmoral privarlos de condiciones decentes de vida o de sacrificio. Y es igualmente inmoral quererlos liberar; ellos dependen de nosotros como nosotros dependemos de ellos. Y están finalmente los animales salvajes a los que no nos ata ninguna relación individualizable, ni afectiva ni vital, sino solamente una relación con su especie. Es pues moral, en el respeto de los ecosistemas, y eventualmente de la biodiversidad, luchar contra las especies dañinas o proteger algunas especies amenazadas. Y es ciertamente inmoral hacer sufrir por placer a un animal salvaje; pero la pesca y la caza no son más inmorales practicadas por el hombre como lo hacen los otros animales entre ellos, desde que el hombre se restrinja al respeto de los equilibrios ecológicos entre especies naturales. Sería evidentemente absurdo querer liberar a los animales salvajes. No porque ellos sean ya "libres" (lo que sin duda tampoco tiene ningún sentido en la naturaleza), sino porque ellos están sujetos de todas maneras a las leyes de la naturaleza y a los comportamientos de todos sus depredadores distintos al hombre.

Ciertamente, esta división tripartita es muy reductora y se la podría matizar hasta el infinito. Sigue siendo cierto que no tenemos los mismos deberes de asistencia con respecto a los animales salvajes que con respecto a los que viven bajo nuestro cuidado. Y sobre todo es verdad que no tenemos ningún deber de "liberación" con respecto ni a los unos ni a los otros. Es pues tan absurdo como inmoral querer liberar a los animales cualesquiera sean ellos. 
